\title{
Dualistic Cultural Characterization of "Tile-Cat" under Tourist Gaze in Ethnic Tourism
}

\author{
Zeng Yan \\ Department of culture and tourism, Yunnan Open University, Kunming, Yunnan Province, China \\ 171908@sina.com
}

\begin{abstract}
As a tourist gaze object "Tile-Cat" is the symbol in the tourism consumption system, has the unique tourism market symbol value, includes self expression and symbol value which represents a mascot, sacred item, totem, natural idol in ethnic area and symbolizes the medium of communication between tourists and ethnic society. In internalization ethnic society "Tile-Cats" has a range of symbolic significances based their culture and nationalidentity and in externalization it communicates a range of information with tourists and their societies, such as change of tourists' status, roles, self-expression and self-identity.
\end{abstract}

Index Terms - Cultural Characterization, Tile-Cat, Tourist Gaze, Ethnic Tourism, Symbol

\section{Introduction}

"Tile-Cat", is a tile element of traditional dwellings above the roof, called the cat because of its image. In Dali, Lijiang, ChengGong, Yuxi, Wenshan, Qujing of Yunnan province it can be find in different style, shape and making techniques (Fig.1), but symbolic significances are similar in diversity ethnic area [1]. In the western of Yunnan many areas, such as Lijiang, Diqing, Naxi people always use "Tile-Cat" that is a fine handwork, exquisite craft, exaggerated form, vivid, lifelike, and creative innovation artwork [2]. Local craftsmen make its head bigger than the body, big mouth, eyes and some multiple cats mix to be a tower, column. The significance of different modeling are diversity and there are more than 250 kinds of modeling according to incomplete statistics [3]. And in Chenggong county, Yuxi and Wenshan city area "Tile-Cat" is similar and makes of yellow figuline by hand. It stand on the roof and there is a eye-catching "The eight diagram" append on its chest properly and a“王”(means "king")pattern is sculptured on the middle of its head as Fig. 1.
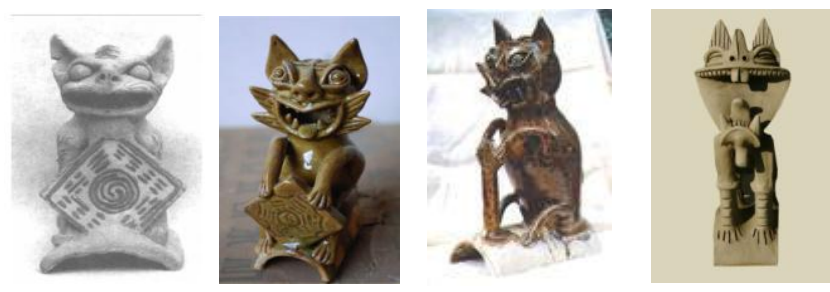

Fig. 1 Tile-Cat of Chenggong, Guanduqu, Yuxi and Dali

The Tile-Cat gets favors of tourists gradually through the technique of craft and artistic modified when it come forth into the tourist market in recent years. As a national tourist gaze object "Tile-Cat" is a consumable of tourists and it contains the value of ethnic culture and reflects the symbol value of tourists at same time [4]. This paper will research the dualistic cultural characterization of "Tile-Cat".

\section{Dualistic Cultural Characterization of "Tile-Cat"}

\section{A. The Cultural Characterization of self expression in the} ethnic society

\section{1) As a mascot}

Auspicious objects derive from a symbol of lucky items using in ritual of fetish, witchery, religion [5]. The conception of mascot is gradually formed in the long-term social practice and on the basis of specific mental environment [6]. Folks think the head and tail punch through mutually, which can absorb the wealth and fortune. And it is also known as "auspicious tiger" that refers to the tiger that can bring good luck for people to drive away demons ,gain supernatural ability avoiding disaster, blessing good luck, getting auspicious spirits. "Tile-Cat" became the helper of normal life, the mental support and reflects the awareness of the nature, yearning for life of people. As a symbol of fortune, the TileCat is indispensable, emotional and cultural symbol.

\section{2) As a talisman}

Talismans express the intangible concept to help people to face all kinds of actual disasters, dangerous, fierce stirred, evils, genies, stealthy false and overcome all kinds of strange confusion and fear in the psychology. As a famous talisman guard folks always put it above the four angles of traditional dwellings roof to prevent the evils and genies. The legend said "Tile-Cat "could eat all monsters and apparitions to protect dwellings in peace and perfect the Feng Shui of dwellings because of its looks like tigers and lions which are ferocious but strong deterrents[7]. "Tile-Cat" records the life experience, is a kind of psychological description for folk disasters, ghosts and gods, also is a kind of mental expression blessing luck and avoiding disaster. With the disaster consciousness it also fully illustrates folks love life, want to realize happiness and wish for the future of the world. "Tile-Cat" is a kind of cultural carrier and ethnic people choose it as a talisman and a culture symbol cultivating the self-identity of the ethnic culture.

\section{3) As a totem}

In Yunnan province ethnic totem animal, tiger totem, is more typical and exists in the Yi, Naxi, Bai, Pumi,Hani and Lahu people[8]. "Tile-Cat" is a continuation of the tiger totem worship so it also be called as "auspicious tiger" and "talisman tiger" because of the shape of forehead “王” which means 
King. For example the Chinese pronounce of family name "tiger" is "mao" (means Cat) but not "hu" (means Tiger) in Zhaotong city lying at northeast of Yunnan, a ethnic minority area; the $\mathrm{Yi}$ people acts "Cat Grandfather and Cat Grandmother" in their original tiger dancing in Chuxiong lying at middle of Yunnan. These two examples illustrate homologous worship between cats and tigers are still keeping in the ethnic area.

\section{4) Natural worship}

Natural faith refers that people regard nature as gods to worship them. This ancient belief regards nature which is great value for human production and life as gods. In the process of field research "Tile-Cat" is a product of natural belief. There is a clear graphics of sun, moon and "The eight diagram" (Fig.2) sculpted on the different part of its body, which shows people want to give the sun's, moon's and Taoism energy to "TileCat" to drive away tragedy and menaces and wish to transfer the opposition to the promotion. "Tile-Cat" is to be a attachment of natural belief, a objective product of natural worship. The "the eight diagram " is a ancient tool of augury so the graphics sculpted on "Tile-Cat" fully represents people hope to forecast the result to judge the direction of development and also illustrates people look forward to happiness life and facing the beautiful future actively.

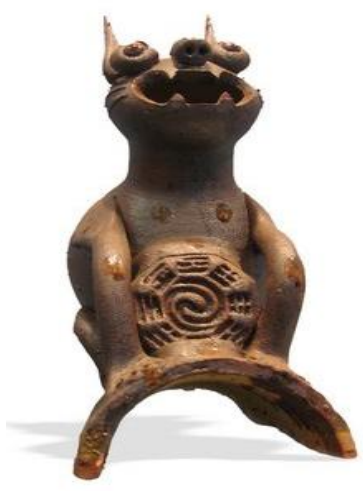

Fig.2 The eight diagrams

\section{5) A ritual of sanctification}

The symbolic significances of "Tile-Cat" will be activated by a unique ritual, "opening-of-light ritual", which is a process of enduing "Tile-cat" with aura and sanctification. The ritual have to choose an auspicious day and be emceed by "Duan Gong" who catches a red rooster meanwhile using any of the magical spells, then he breaks the cockscomb by the teeth and drop the blood of the comb on the "Tile-Cat" 's eyes, nose, mouth, ears and its body. After that he puts the pine nuts, seeds, grain sorghum, jujube, tea, and a red line into the mouth, then burns yellow paper (The special paper to communicate with Sheol and this world) with reading the magical spells. The next step is putting the chicken into the pot boiled to a half cooked and removes it standing in the basin with the head toward the sky and then incensing for a peace offerings. Finally, "Duan Gong" steps ladder on the roof and lies "Tile-Cat" on the ridge of roof (Fig.3) and it becomes a spirit item.

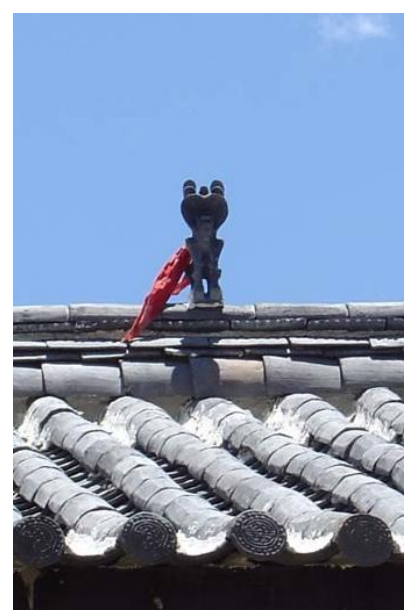

Fig.3 "Tile-Cat" on the roof

In conclusion "Tile-cat" forms a range of symbolic significance in ethnic residents' life and fuses totem worship, natural worship and mundane life together. In a certain degree it shows the cognition and perception of ethnic residents to the cosmic order and existence of supernatural power. Those entire symbols be activated by the sacred ritual that endowed "Tile-Cat" with the all symbolic significances, so it to be a real supernatural cat.

\section{B. The Cultural Characterization of communication with external society}

As a symbol of a medium communicating with tourists and external societies the main object of "Tile-Cat" expresses the change of tourists' role, status and shows tourists' selfexpression, self-identity [9].

\section{1) Symbolizing the change of tourists' position}

Tourism is an alternative way of life. It distances the space distance and mental distance of daily life environment and avoids people involving into a long-term cycle life. In the ethnic tourism pattern, tourists are consumers to enjoying tourism products and services, so they have a higher position in the tourism activities. Tourists feel very happy for getting "Tile-Cat", an auspicious item, which will bring good luck. "Tile-Cat" made by ethnic handicraftsmen who would like to sale it to tourists, meanwhile to acknowledge those consumers who cognize the symbol value, so tourists can feel the respect and gladness coming from the residents. Tourists have become a centre of tourism activities and the position of tourists has raised immediately comparatively normal persons in their daily life.

\section{2) Symbolizing the change of tourists' role}

Role is one of the expression of identity, is also the symbol of the society. The interpersonal relationship represents the role in daily life and the relationship between the characters. When tourists enter in "Tile-Cat" workplace or 
shops the tourists transform from the "self" in daily life to "new self" in tourism time and space. Tourists abandon the normal life briefly and experience the national culture of "TileCat" like a "local minority". The process of consumption is not only a transformation of tourists' roles and also a course of its symbolization.

\section{3) Symbolizing the medium of communication between different cultures}

As externalization of symbol, "Tile-Cat" is a medium to communicate with tourists' community and is a bridge between local ethnic culture, the tourists' community culture and the world culture [10]. "Tile-Cat" is a result of ethnic culture. When tourists take it back to their communities as a souvenir, present or show their relatives and friends as a gift and tell them it's symbol significance "Tile-Cat" will to be a symbol that represents the ethnic culture begin to communicate with the different community in multi-dimensional culture.

\section{4) Symbolizing self-expression and self-identity of tourists}

The ego is refers to the individual characteristics of their personal and social identity of consciousness and feeling. The development of self is a range of sustaining process of communication between "subjective self" and "objective self" in social interaction, is a process of "subjective self" adjustment according the constantly changing "objective self" [11] [12] [13]. So when self internalize the group ethical value to be own values "objective self" or self-identity formed [14]. In the tourism consumption when tourists back to the residence to display "Tile-Cat", which is a presentation of tourists themselves who regard "Tile-Cat" as prop to look forward to communities' attitudes to themselves. The presentation of tourism souvenirs is a part of the presentation of tourists facing the communities. In the presentation tourists want to show not only they are world travellers, but also tasty persons of ethnic culture, so "Tile-Cat" is a symbol of tourists' externalism. Some of the time tourists buy "Tile-Cat" just to leave own memory and it is still a self performance prop confirming and identifying with the identity in ethnic tourism.

\section{Conclusion}

The dualistic cultural characterization of "Tile-Cat" represents internalization and externalization of symbol significance. As an internal symbol of communication it symbolizes a mascot, sacred item, totem and natural idol, which is an expression based on ethnic culture. As an external symbol of communication it represents self values to express aesthetic standards of tourists. As a medium of communication between tourists and diverse societies it creates multidimensional communication of social culture, national culture and tourists' social culture to transmit self-expression and selfidentity of tourists.

\section{Acknowledgment}

Grateful thanks are due to many people who helped me with my fieldwork. My thanks go to my dear schoolfellow Xu Zhengxiang who give me many supports for survey and the other team number, Wang Xia, Li Zhi who clear my thinks and give me many advices.

\section{References}

[1] Gui Rong, "Yunnan Minority Residence Spirit Anthropology Study," Qinghai National Research, vol. 1, 2008.

[2] Dong Juying, "Tile-Cat", Nation Today, vol. 3, 1999.

[3] Dong Juying, "Yunnan folk town beast art", Decoration, vol. 4, 1998.

[4] Dimanche and Samdahl, "Leisure as -- Consumption: a conceptualization and prospects for future research", Leisure Studies, vol. 4, 1994, pp. 119-129.

[5] Tao Siyan, "Theory of the talisman and auspicious," Journal of Jiangsu Administration Institute, vol. 4, 2005, pp.24

[6] Zhong Jingwen, "The description of Folklore," Shanghai Wenyi Press, Shanghai, 1998, pp. 187.

[7] Yunnan tea net, "The south of clouds, the culture of Yunnan unique town ridge beast - tile cat": http://www.yuncha.com.cn/bbs/viewthread. PHP? Tid 427.

[8] Gui Limei, "Yunnan minority residence spirit content analysis," Journal Of Yunnan Nationalities Institute, vol. 4, 2005, pp. 54-57.

[9] Xie, Yanjun etc, "The tourism experience research - empirical science," China Tourism Press, 2010, pp. 37-38.

[10] King, J. C. H. "Marketing Magic: Process, identity and the creation and selling of native art," Lanham/New York/Oxford: University Press of America, Inc.

[11] Zhang Xiaoping, "National tourism anthropology perspective," Yunnan University Press, 2009, pp. 211.

[12] Zhang Xiaoping, Li Wei, "Tourism anthropology," Nankai University Press, 2010.

[13] Peng Zhaorong, "Tourism anthropology," University of Nationalities Press, 2004, pp. 267-273.

[14] David popuno, "Sociology", Chinese People's University Press, 2002, pp.148-190. 